\title{
Application prospective of nanoprobes with MRI and FI dual-modality imaging on breast cancer stem cells in tumor
}

\author{
Hetao Chen ${ }^{1 \dagger}$, Yu Wang ${ }^{2 \dagger}$, Tong Wang ${ }^{1 \dagger}$, Dongxing Shi ${ }^{1}$, Zengrong Sun ${ }^{1}$, Chunhui Xia ${ }^{2 *}$ and Baiqi Wang ${ }^{1^{*}}$
}

\begin{abstract}
Breast cancer (BC) is a serious disease to threat lives of women. Numerous studies have proved that BC originates from cancer stem cells (CSCs). But at present, no one approach can quickly and simply identify breast cancer stem cells (BCSCs) in solid tumor. Nanotechnology is probably able to realize this goal. But in study process, scientists find it seems that nanomaterials with one modality, such as magnetic resonance imaging (MRI) or fluorescence imaging (FI), have their own advantages and drawbacks. They cannot meet practical requirements in clinic. The nanoprobe combined MRI with FI modality is a promising tool to accurately detect desired cells with low amount in tissue. In this work, we briefly describe the MRI and FI development history, analyze advantages and disadvantages of nanomaterials with single modality in cancer cell detection. Then the application development of nanomaterials with dualmodality in cancer field is discussed. Finally, the obstacles and prospective of dual-modal nanoparticles in detection field of BCSCs are also pointed out in order to speed up clinical applications of nanoprobes.
\end{abstract}

Keywords: Breast cancer, Cancer stem cells, Magnetic resonance, Fluorescence, Imaging

$\mathrm{BC}$ is serious malignant tumor to threat lives of women. The new cases reach 1,300,000 annually worldwide. Despite identification and treatment technologies have achieved great progress, $\mathrm{BC}$ is still the second largest cause of tumor-related deaths of women [1]. BC does not have any symptom at early stage. The unformed nodules are too small to be perceived in clinic exams. Usually when patients find tangible lumps, metastasis can happen in the whole body and tissue-focused therapy is highly likely to fail $[2,3]$. Therefore, the diagnosis and cure of $\mathrm{BC}$ at early stage is highly necessary to decrease mortality and improve the quality of the lives of patients.

\section{Breast cancer stem cells}

With accumulating basic and clinical knowledge, the treatment technologies of $\mathrm{BC}$ are continuously created, and survival period of patients is gradually prolonged.

\footnotetext{
*Correspondence: chunhuixia1969@sohu.com; wbqpaper@126.com ${ }^{\dagger}$ Hetao Chen, Yu Wang, Tong Wang contributed equally to this work

${ }^{1}$ Department of Occupational and Environmental Health, School of Public Health, Tianjin Medical University, No. 22, Qixiangtai Road, Heping District, Tianjin 300070, China

2 Department of Chemistry, Qiqihaer Medical College, Qiqihaer 161006, Heilongjiang Province, China
}

Although the 5-year overall survival of BC reaches $91 \%$ [1], it is still unavoidable that about $30 \%$ patients happen recurrence and metastasis [4]. In recent years, scientists find that $\mathrm{BC}$ is a typical disease of stem cells, whose recurrence and metastasis are close related to the CSCs (Fig. 1) [5].

CSC hypothesis proposes that one population with rare quantity have the capability of self-renewal, proliferation and high resistance to chemotherapy drugs [6]. The CSCs hypothesis supplies a new clue for diagnosis and therapy of cancers. In 1997, Bonnet et al. [7] firstly indentified a common immunophenotype of leukemic stem cells with self-renewal potential. Therefore, CSC existence was firstly proved. In 2003, AI-Hajj successfully isolated BCSCs from human BC cell line. One thousand of these cells were sufficient to generate tumors when xenotransplanted into NOS/SCID mice, although around fifty thousand were needed in the unsorted population. That work demonstrated that BC originated from BCSCs [8].

The proliferation of BCSCs is disordered and out of programming, and BCSCs lack differentiation and mature capability. Moreover, BCSCs can accumulate 


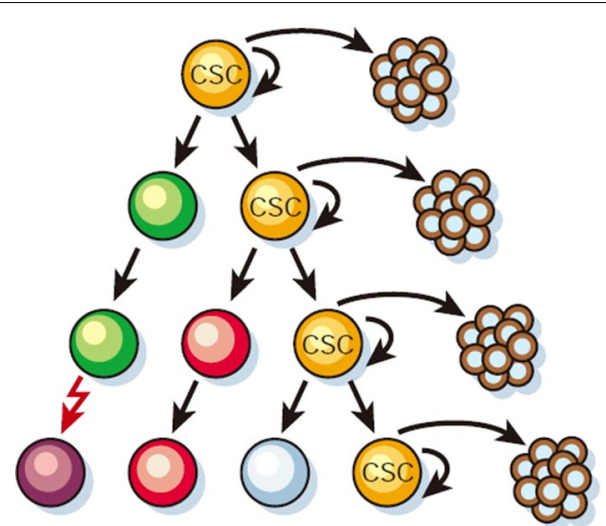

Fig. 1 Most cancer cells have only limited proliferative potential, only CSCs (yellow) have the ability to proliferate extensively and form new tumors [5] [Adapted by permission from Macmillan Publishers Ltd: [Nature] (Ref.5), copyright (2001)]

replication error, furthermore, lead to tumor occurrence. BCSCs can also escape chemotherapy, achieve drug resistance ability through mutation, and accelerate self-renewal process after drug therapy [9]. These factors promote breast cancer recurrence. In addition, activity of BCSCs can enhance and ratio of side population will increase after radiation treatment. Furthermore, BC has capability to resist radiotherapy [10, 11]. Although BCSCs play critical roles in occurrence, development and recurrence of $\mathrm{BC}$, the amount of $\mathrm{BCSCs}$ in tumor tissue is less than $2 \%$ [12]. Therefore, isolation, detection and labeling BCSCs are difficult. But they are still study focuses in $\mathrm{BC}$ field at present.

The isolation is foundation and key of BCSCs investigation. At present, the approaches of BCSCs isolation include surface marker sorting, aldehyde dehydrogenase activity assay, flow cytometry sorting side population, etc. [8-15]. Almost all of the described methods are based on optical change before and after substrates interacting with antibodies. Then BCSCs are isolated by flow cytometry. These methods are able to rapidly isolate, purify BCSCs. They push forward the advancement of BCSCs research, and enrich understanding of BCSCs for scientists $[16,17]$. However, the former approaches are mainly well applied in cell line level; and they have difficulties to track BCSCs in solid tumors in vivo. In this side, fluorescence quantum dot (QD) probes have intrinsic advantages in detecting cancer cells.

\section{Fluorescent quantum dot probes staining BC and other cells}

The QD probes based on semiconductor quantum dots have obvious advantages. They have broad excitation band, narrow and symmetrical fluorescence peak, tunable fluorescence wavelength with adjusting diameter and components of nanoparticles and strong antiphotobleaching capability, comparing with traditional organic dyes. The fluorescence intensity and stability of single QDs are 20 and 100-200 times higher than that of single organic fluorescence molecule, in respectively [18]. In 1998, Alivisatos and Nie groups published papers about QDs applications in biological systems in Nature magazine at the same time, which marked era arrival of fluorescence QD labeling biological molecules $[19,20]$.

QD probes can specially label biomarkers on tumor cell surface and accurately label subtle subcellular structure. Moreover, two or more different QDs can be excited by sole light source (Fig. 2). Wu et al. linked QDs with immunoglobulin G (IgG) and streptavidin to label breast cancer marker Her2 on the surface of fixed and live cancer cells. The QD probes could specifically label the desired targets and were brighter and considerably more photostable than comparable organic dyes. Their study demonstrated that QD probes could be very effective in cellular imaging and offer substantial advantages over organic dyes in multiplex target detection [21]. Gao and O'Regan et al. conjugated Her2, ER, PR, mTOR and EGFR with QDs to obtain nanoprobes. Their QD probes could not only detect tumor biomarkers in both cultured human $\mathrm{BC}$ cells and on single paraffin embedded clinical tissue sections, but also quantify ER, PR and Her2 receptors. Their study suggested that QD probes were well suited for molecular profiling of tumor biomarkers in vitro [22]. Pang and Li et al. even used QDs immunofluorescence technology to quantify HER2 expression in BC [23]. Liu and co-workers used QD probes to explore basic scientific problem, $\mathrm{BC}$ invasion. They obtained exciting results [24]. Many groups, including our research team, have carried out relevant studies and the results were interesting [25-31] (Fig. 3).

QDs have excellent optical properties, therefore, they have great potential to be applied in tumor imaging field as fluorescence probes in vivo. Gao and co-workers successfully attempted. They encapsulated luminescent QDs with $\mathrm{ABC}$ triblock copolymer and linked this amphiphilic polymer to tumor-targeting ligands and drug-delivery functionalities. In vivo targeting studies of human prostate cancer demonstrate that QD probes could accumulate at tumor sites through passive and active targeting effects. The QD probes displayed sensitive and multicolor fluorescence imaging of cancer cells under in vivo conditions (Fig. 4) [32]. Their study and results of other groups demonstrated that QD probes could probably be used for ultrasensitive and multiplexed imaging of molecular targets in vivo [33, 34]. Although QD probes have their own 


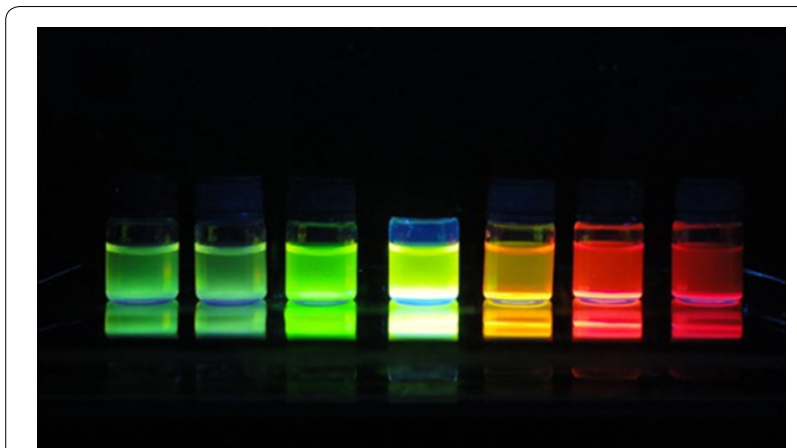

Fig. 2 Emission colors of QDs excited by UV

advantages, it also has some unavoidable disadvantages in vivo detection cells with low amount of quantity. The wavelength of emission photon of QD is in visible range, which is also emission band of tissue autofluorescence. Moreover, the fluorescence of QD has low spatial resolution in organ analysis. These drawbacks can effectively be compensated by the magnetic resonance imaging (MRI).

\section{MRI labeling BC and other cells}

MRI has rapidly developed and widely used in biology and medicine field since it was firstly applied in human disease diagnosis in 1973 [35]. MRI is based on magnetic resonance signal change of water nuclei of hydrogen atoms under the interaction of an external magnetic field [36]. MRI has its own advantages in tumor detection at early stage in vivo.

The contrast agent is an important part of MRI technology, and it is estimated that more than $35 \%$ clinical MRI diagnosis must use contrast agent [37]. At present, gadopentetatedimeglumine (DTPA-Gd) is most commonly used in clinic. Although the proton T1 relaxation time decreases and the clarity of MRI improves after DTPA-Gd intravenous injection, the contrast agent belongs to small molecular compound and its price is relatively expensive. Moreover, the contrast agent does not have tissue or organ targeting effect, and its retention time is short. These disadvantages limit its further applications in clinical practice [38].

With nanotechnology development, scientists began to explore application possibility of magnetic nanomaterials
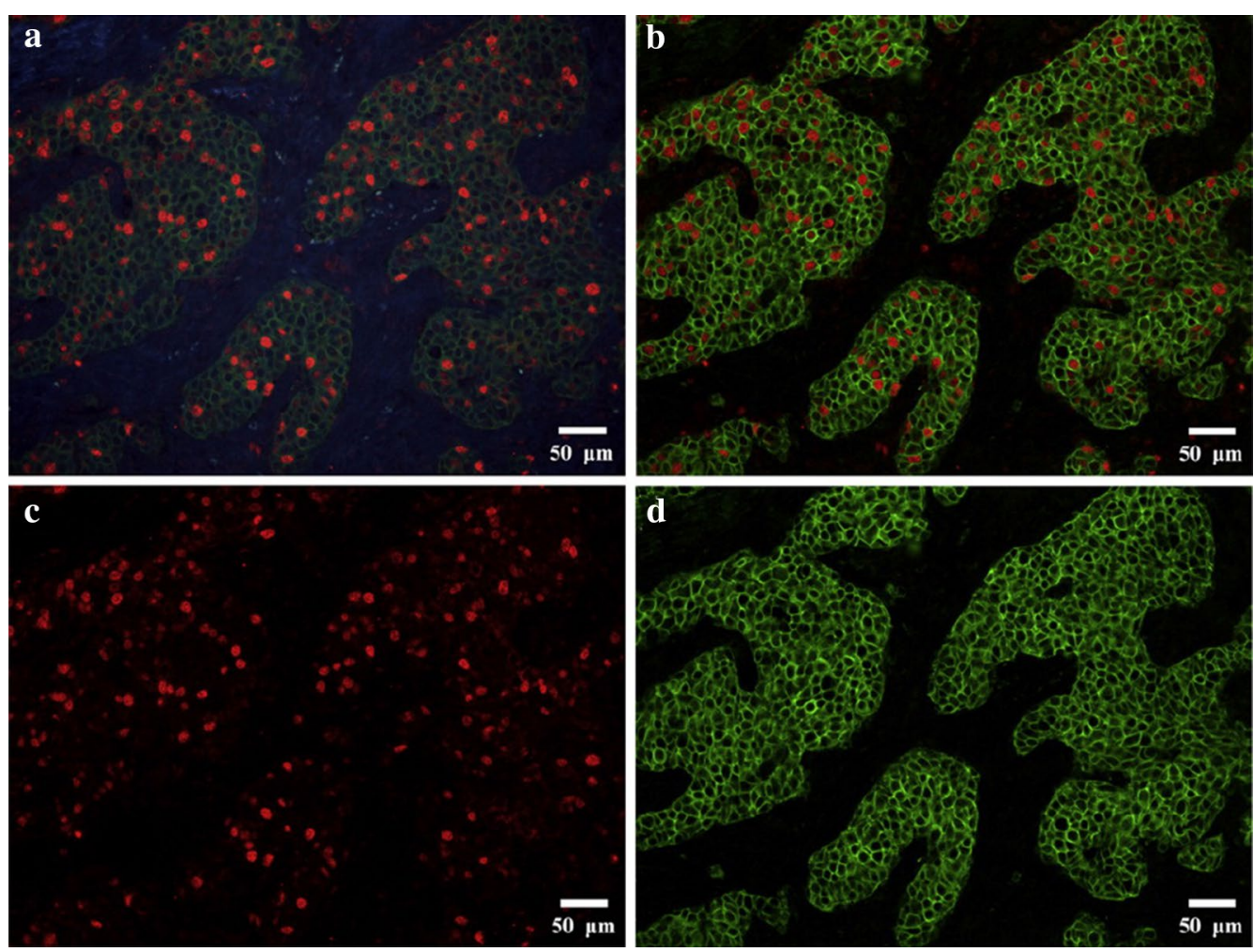

Fig. 3 QD-based double-color in situ fluorescent imaging for Ki67 andHER2 in BC. QD-based double-color images for Ki67 andHER2, Ki67was expressed as clear red fluorescence, HER2 as bright green fluorescence (a); the spectral images of Ki67 and HER2 co-expressions were obtained by CRi Nuance multispectral imaging system, which could unmix the images into single color images (b); the single red fluorescent image representing Ki67 at the emitting wavelength of $655 \mathrm{~nm}$ (c); and the single green fluorescent representing HER2 at the emitting wavelength of $525 \mathrm{~nm}$ (d). 200x , scale bar $=50 \mu \mathrm{m}[28]$ 

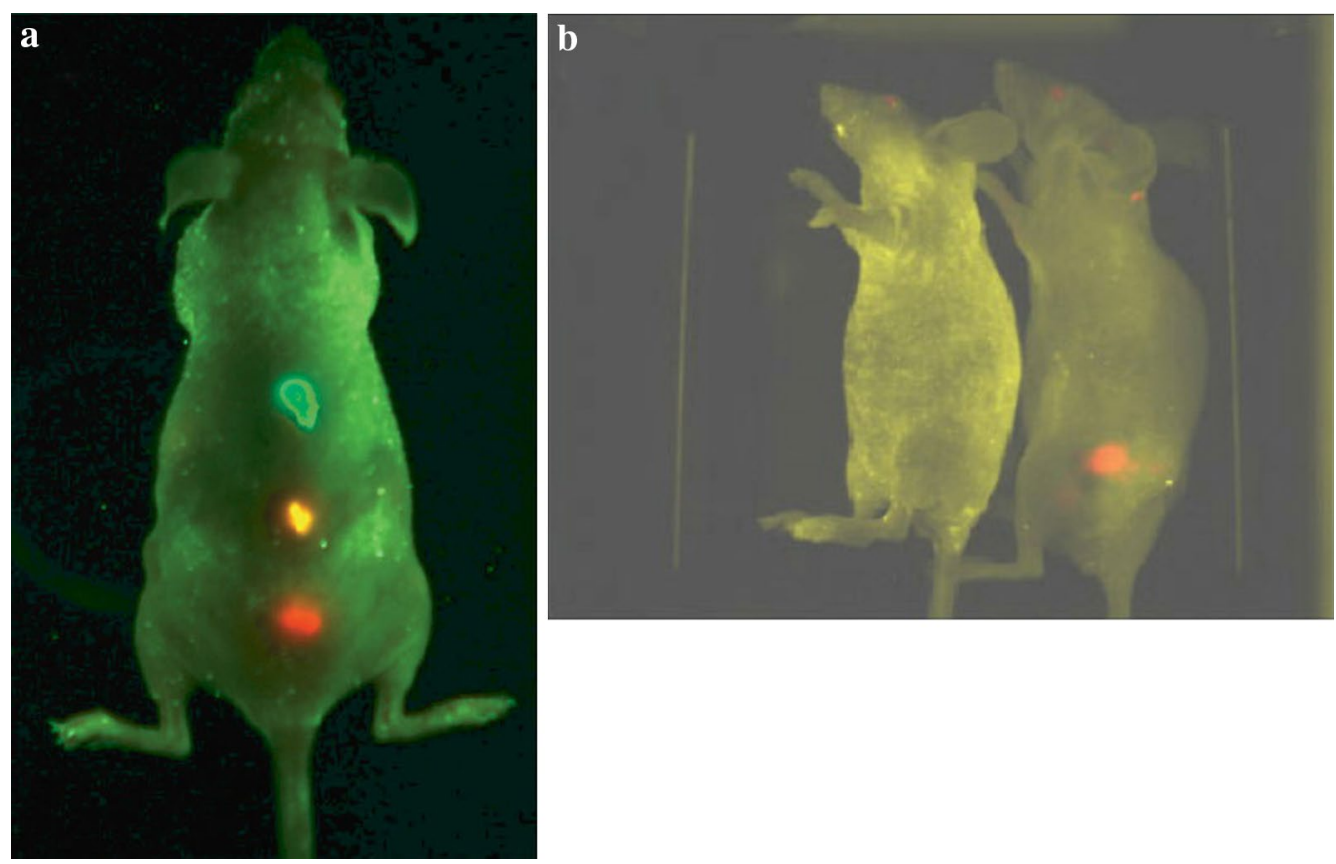

Fig. 4 a In vivo simultaneous imaging of multicolor QD-encoded microbeads injected into a live mouse (b) Molecular targeting and in vivo imaging of a prostate tumor in mouse using a QD-antibody conjugate (red) [32]

as imaging contrast agent in MRI [39]. Up to now, most studies focus on superparamagnetic iron oxide (SPION). The core crystal structure of SPION is $\mathrm{Fe}_{2} \mathrm{O}_{3}, \mathrm{Fe}_{3} \mathrm{O}_{4}$ or their composite. The SPION surface is modified with some functional molecules, such as dextran, citrate or polyethylene glycol, in order to improve stability and biocompatibility of contrast agent [40-42]. SPION has magnetic property. While the size of SPION particles reaches nanometer level, the single magnetic domain can be formed. Therefore, the iron oxide nanoparticles appear superparamagnetic property [43]. Then SPION nanoparticles can further conjugate with biofunctional molecules to fabricate targeting nanoprobes, which are able to detect BC cells and other cells. Salouti and Shayesteh et al. prepared SPION coated with dextran and bombesin to produce a targeting contrast agent (DSPION-BBN) for detection of $B C$ using MRI. They found that DSPIONBBN possessed good diagnostic capability as a contrast agent, with appropriate signal reduction in $\mathrm{T}_{2}$-weighted color map MR imaging in mice with BC [44]. On SPION surface, other functional molecules can also be conjugated; furthermore, SPION bioconjugates possess more functions. Zheng and Wang et al. prepared superparamagnetic poly(lactic-co-glycolic acid) (PLGA) microcapsules $\left(\mathrm{Fe}_{3} \mathrm{O}_{4} / \mathrm{PLGA}\right)$ for the application in ultrasound/ MRI dual-modality biological imaging of BCs in vitro and in vivo. Their results showed that the bioconjugates had good ultrasound imaging and MRI imaging capability and provided an alternative strategy for highly efficient imaging guided non-invasive BC therapy [45]. Other research groups also obtained similar good results [4648] (Fig. 5).

SPION has good properties for MR imaging, but it also has some intrinsic drawbacks. In MR imaging, the SPION shortens the $\mathrm{T}_{2}$ time, and makes the $\mathrm{T} 2$ weighted image darker, thus enhances the contrast. Therefore, MRI signal is weak when few of CSCs in tissue is detected. In addition, a study has demonstrated that the amount of iron oxide consumed by the cells was 10 times over the amount of endogenous iron in detection process. This could directly induce some toxicities and side effects to the cells [49]. Moreover, the endosomes containing particles of iron oxide were particularly sensitive to external magnetic field. The endosomes could be arranged along the outer magnetic field and the bead string structure could be formed in the intracellular [50]. All of these drawbacks influence the quality of MR imaging CSCs.

According to the former analysis, nanomaterials with single imaging modality, whatever is FI or MRI modality, cannot sensitively and accurately label and track few CSCs in solid tumors because of their natural advantages and disadvantages (Table 1). But once the nanoprobes combined with FI and MRI modality, namely FI-MRI dual-modality, are possibly to label and track CSCs in in vivo. 


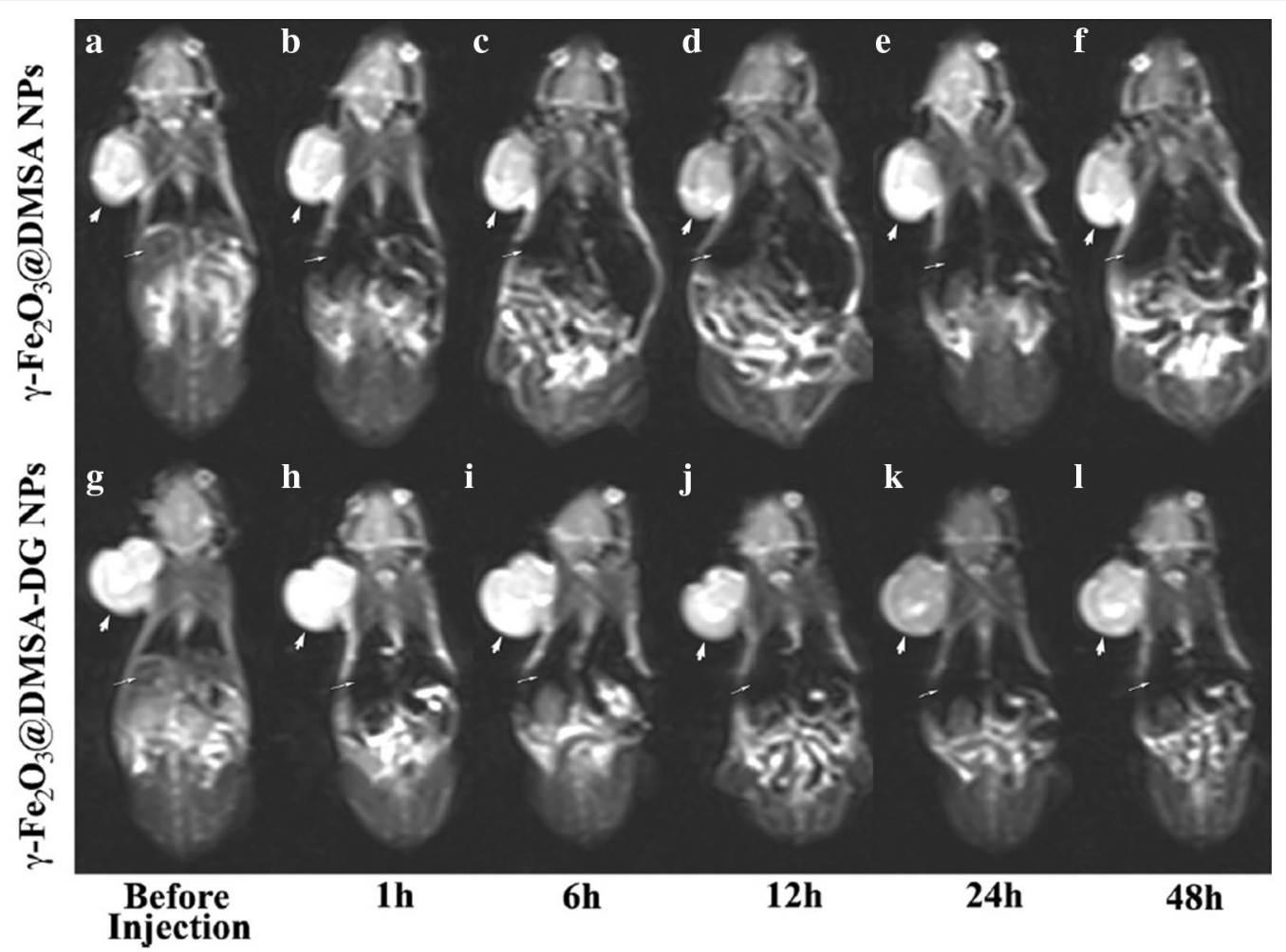

Fig. 5 1.5-T MRI turbo-spin-echo-T2-weighted (5500/100) dynamic imaging of human MDA- MB-231 breast cancer xenografts. a-f Injection of $\mathrm{\gamma}-\mathrm{Fe}_{2} \mathrm{O}_{3} @ \mathrm{DMSA}$ NPs showed that the tumor (thick white arrows) signal intensity decreased at $12 \mathrm{~h}$ which returned to basal levels by $24 \mathrm{~h}$. $\mathbf{g}-\mathbf{I}$ Injection of $\mathrm{Y}-\mathrm{Fe}_{2} \mathrm{O}_{3} @ D M S A-D G$ NPs showed that the tumor signal intensity decreased between 12 and $48 \mathrm{~h}$, with the most hypointensity observed at $24 \mathrm{~h}$. The signal intensity in the liver (thin white arrows) significantly decreased after injection of $\gamma-\mathrm{Fe}_{2} \mathrm{O}_{3} @ \mathrm{DMSA} N \mathrm{Ns}$ or $\gamma$-Fe $\mathrm{O}_{3} @ \mathrm{ODMSA}$-DG NPs [48]

Table 1 Advantages and drawbacks of fluorescence and magnetic resonance imaging

\begin{tabular}{lll}
\hline & Fluorescence & $\begin{array}{c}\text { Magnetic resonance } \\
\text { imaging }\end{array}$ \\
\hline $\begin{array}{ll}\text { Spatial resolution } \\
\text { Sensitivity }\end{array}$ & Low & High \\
Specificity & Weak & Low \\
& & T1 imaging is better for \\
& & anatomic structure; \\
& & T2 imaging is better for \\
& tissue lesions \\
Penetration depth & Shallow & Deep \\
Acquisition time & From a few seconds to a & From several minutes to a \\
& few minutes & few hours \\
Traumatic & Noninvasion & Noninvasion \\
\hline
\end{tabular}

\section{FI-MRI dual-modality nanoprobes indentifying BC and other cells}

Up to now, the nanoprobe studies about FI-MRI dual modality for labeling cells have achieved advancement worldwide. Most of the studies were based on nanosized iron oxide to fabricate dual-modality nanoprobes. Shi and Yang group prepared monodisperse silica-coated manganese oxide nanoparticle (NPs) covalently conjugated with Rhodamine B isothiocyanate (RBITC) and folate (FA) on surface. The prepared nanoprobes could specifically target cancer cells overexpressed FA receptors. And the probes were excellent platform for both MRI and FI in various biological systems at the same time [51]. Lee et al. constructed dual-modality nanoprobes based on a $\mathrm{Fe}_{3} \mathrm{O}_{4}$-encapsulated block copolymer conjugating with fluorescent dye Sulforhodamine 101. The nanoprobes could be internalized into BC cells, which were probably used in biomedical diagnosis fields [52]. While $\mathrm{Xu}$ and co-workers fabricated an FIMRI dual-modality imaging nanoprobe based on gadolinium oxide and aptamer-Ag nanoclusters. Using this nanoprobe, MCF-7 BC cells could be effectively tracked by FI and MRI in vitro [53]. Kobayashi et al. used small particle of iron oxide (SPIO) and quantum dot (QD) to dual-label human $\mathrm{BC}$, and tracked $\mathrm{BC}$ in the lymphatic system in mice in vivo MRI and FI imaging. Their study demonstrated that nanoprobes with MRI and FI dualmodality was possible to depict marco and early micrometastase with the lymphatic system [54]. Zhang et al. prepared SPION coated with copolymer of chitosan and 
polyethylene glycol (PEG), labeled with fluorescent dye and conjugated with monoclonal antibody against the neu receptor (NP-neu). The bioconjugates could accurately label breast tumors with MRI and optical dualmodality [55].

Halas and his assistants constructed nanoshells (NS) by coating a gold shell with a silica epilayer doped with $\mathrm{Fe}_{3} \mathrm{O}_{4}$ and the fluorophore indocyanine green (ICG). The NS enhanced the fluorescence of ICG through efficiently integrating nanoparticles $\mathrm{Fe}_{3} \mathrm{O}_{4}$ into the requisite spacer layer between the metallic shell layer and the ICG fluorophore. The nanocomplexes could well target and image SKBR3 cells [56]. Hyeon and his co-workers synthesized nanoparticles by decorating the surface of mesoporous dye-doped silica nanoparticles with $\mathrm{Fe}_{3} \mathrm{O}_{4}$ nanocrystals loading doxorubicin (DOX). The nanocomplexes could passively target and accumulate at the tumor sites by both T2 MRI and FI. The versatile nanoplatform was a good imaging and drug delivery system for cancer detection and therapy (Fig. 6) [57]. Shin and Cheon fabricated
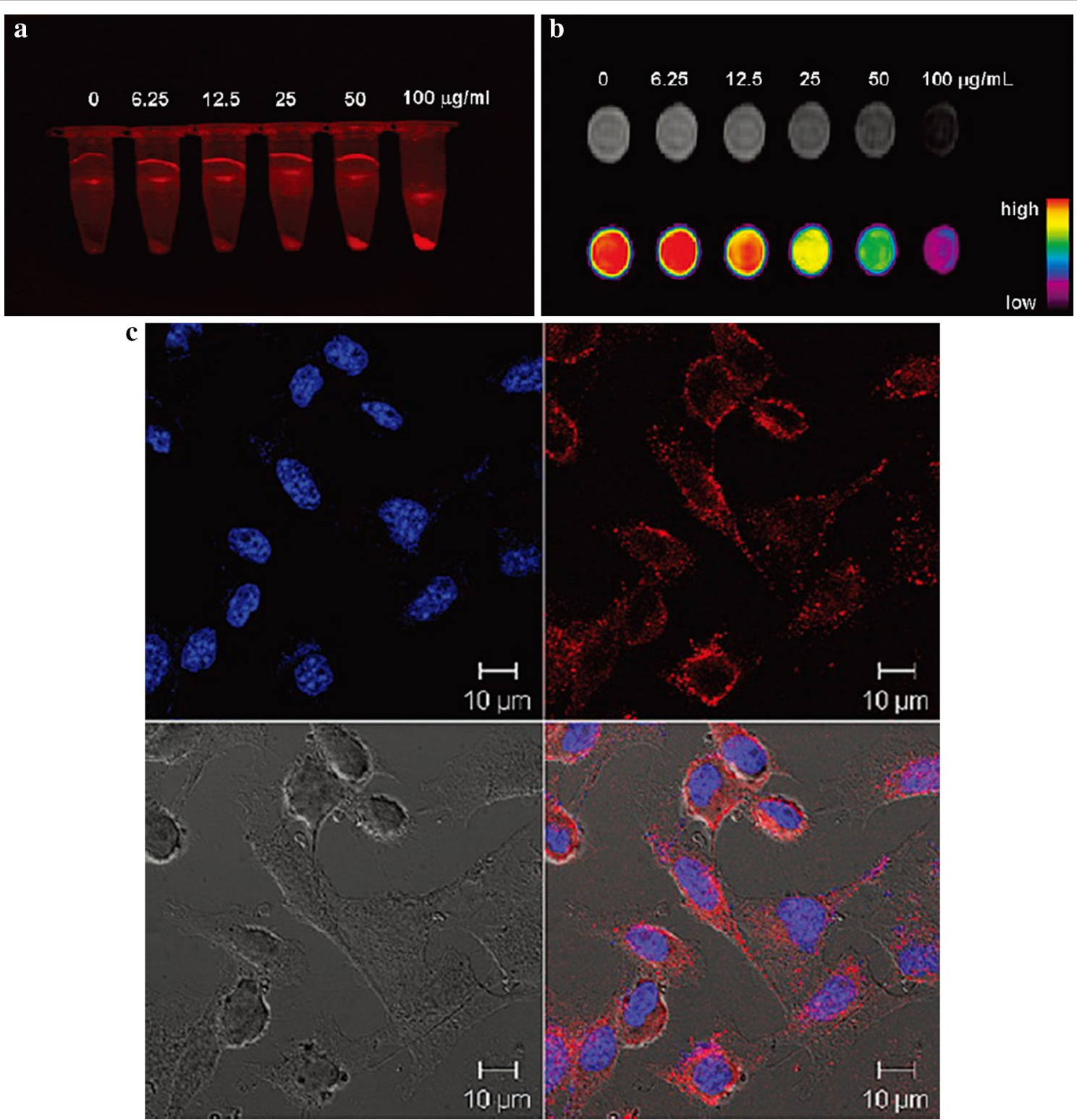

Fig. 6 In vitro multimodal imaging with nanoprobes. (a) Fluorescence image of cell pellets and (b) MR (upper) and its color mapped (lower) images of dispersed cells in agarose. (c) Confocal laser scanning microscopic images [57]. Reprinted with permission from (J Am Chem Soc. 2010; 132: 552-557). Copyright (2010) American Chemical Society 
core-satellite nanoparticles through conjugation of Rhodamine-dye-doped silica $\left(\mathrm{DySiO}_{2}\right)$ nanoparticles with water-soluble magnetism engineered iron oxide (MEIO) nanoparticles and HmenB1 antibodies by using proper cross-linkers. The prepared nanoparticles had excellent dual-modal imaging properties for detection of polysialic acids expressed on various cell lines [58]. Other several research groups used dual-modality nanoprobes to detect or analyze cells, the results were very exciting [5966]. These results indicate that nanoparticles with MRI and FI dual-modality are able to label and track targeting cells in tissue or solid tumors.

In detection of stem cells study using dual-modal nanoprobes, several groups have already made progress. Shen et al. constructed nanometer-sized cationic polymersomes loaded with supermagnetic iron oxide nanoparticles and quantum dots. The synthesized cationic polymersomes could act as an effective and safety carrier to transfer image labels into neural stem cells. The monitored cells could be detected up to 6 weeks by MRI and up to 4 weeks by FI [67]. Liu group prepared multifunctional nanoprobes (MFNPs) using upconversion nanoparticles as core, a layer of ultrafine iron oxide nanoparticles as intermediate layer and a gold layer as outer layer. The prepared MFNPs could accurately label mouse mesenchymal stem cells (mMSCs), but they did not influence viability and differentiation ability of mMSCs. In vivo experiments, the nanoprobe exhibited ultrahigh sensitivity. Using upconversion and MRI approaches, MFNP-labeled mMSCs could be well tracked under a magnetic field (Fig. 7) [68].

In mesenchymal stem cell detection, Sung and his co-workers prepared magnetic nanoparticles (MNPs) coated with a silica shell, and then rhodamine B siothiocyanate (RITC) was incorporated into the silica shell. Thus, the $\mathrm{MNP} @ \mathrm{SiO}_{2}$ (RITC) had a bifunctional property which enables dual modality detection by MRI and optical imaging. The nanoparticles were further modified with PEG groups in order to improve their biocompatibility. The fabricated nanoparticles could accurately label human mesenchymal stem cells (hMSCs) in vitro and in vivo with optical and MRI (Fig. 8) [69]. Park et al. used MRI/FI nanoparticles as transfection agent for gene delivery and cell tracking of hMSCs. The nanoagent did not only display high transfection efficiency in hMSCs, but also exhibit good MRI and FI capability over 14 days [70]. Other research groups used similar bifunctional nanoparticles to label MSCs and similar results were obtained [71-76].

Although these studies are very exciting, but some drawbacks existing in present probes should be perceived. Firstly, optical stability of organic dyes is relatively weak, which can decrease the optical stability of nanoprobes; secondly, the diameter of dual-modality nanoprobes synthesized by polymer composites is relatively larger. This influences penetration capability of
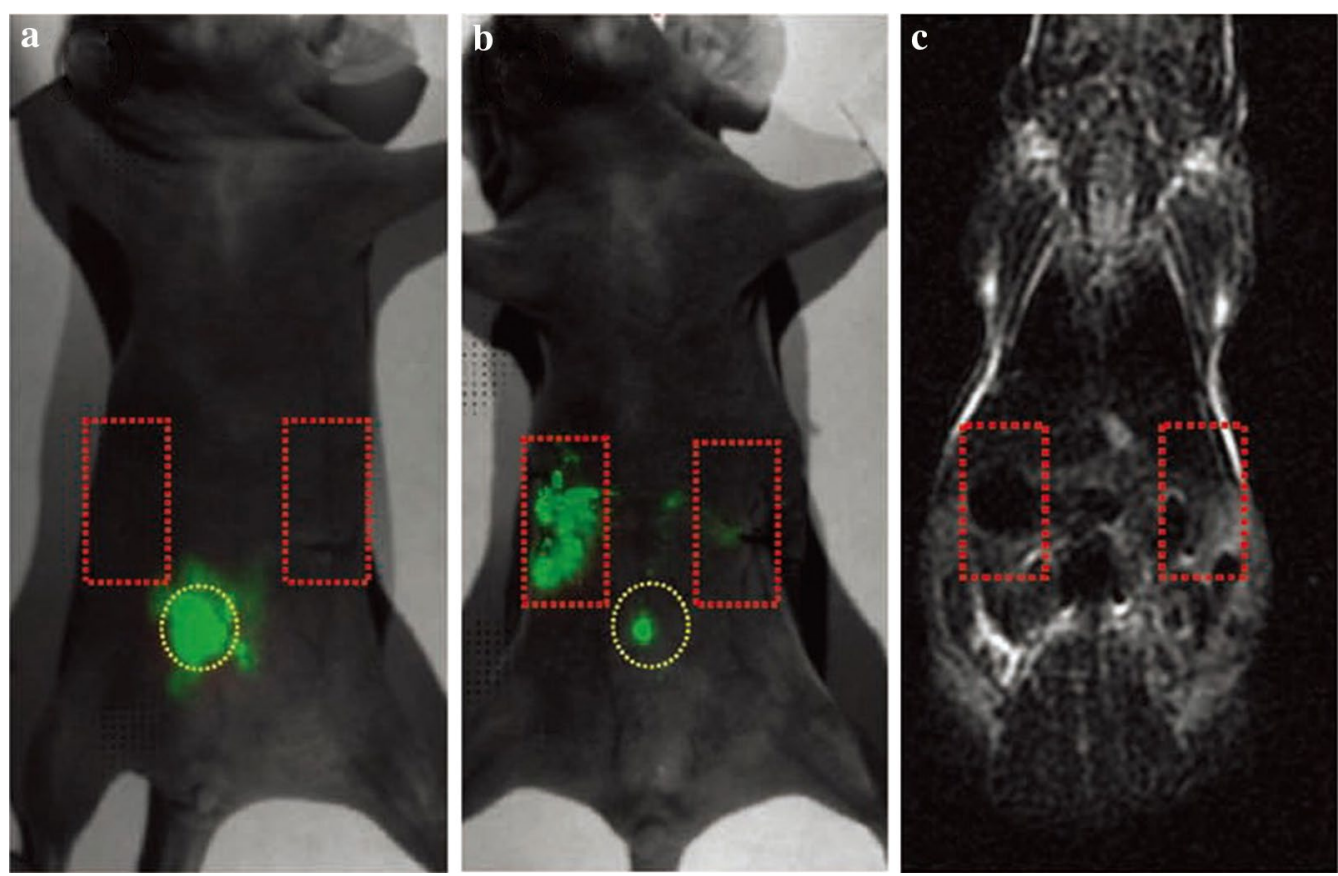

Fig. 7 Upconversion fluorescence images of a mouse injected with multifunctional nanoparticles-labeled mMSCs taken right after injection (a) and $6 \mathrm{~h}$ after injection (b) in the presence of a magnetic field. (c) In vivo MR image of the same mouse in (b) [68] 


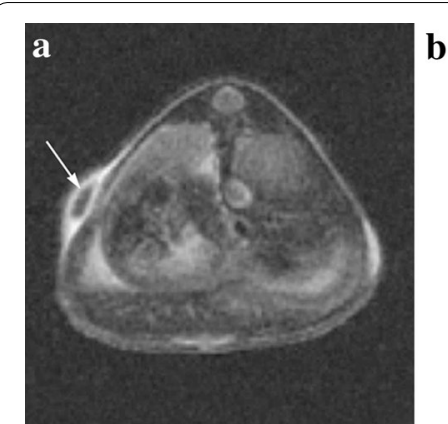

b

Fig. 8 In vivo MR imaging (a) and fluorescence imaging (b) of nude mouse after subcutaneous injection of labeled and unlabeled human mesenchymal stem cells with MNP@SiO2(RITC)-PEG ( $1=1 \times 10^{5}$ unlabeled human mesenchymal stem cells for control, $2=1 \times 10^{6}$ labeled human mesenchymal stem cells, $3=1 \times 10^{5}$ labeled human mesenchymal stem cells). Labeled human mesenchymal stem cells are clearly seen as dark dot (arrow) in subcutaneous layer of nude mouse on axial scan of fast spin echo sequence. Fluorescent signal of subcutaneously injected human mesenchymal stem cells is detected at injection sites of labeled cells. Injection sites of unlabeled cells shows autofluorescence-induced artifact [69]

nanoprobes among tissue cells and limits nanomaterials further application. In addition, multi-layer assembled nanoprobe has complex structures and is relatively expensive, which is difficult to apply in clinical practice. However, once these drawbacks are overcome, dualmodality or multi-modality nanoprobes will be rapidly applied in detection and therapy fields of BCSCs and other cancer stem cells.

\section{Application prospective of nanoprobes with MRI-FI dual-modality on detecting BCSCs}

MRI-FI Dual-modality nanoprobes are integration of two different imaging probes with single modality. These nanoprobes can be detected under FI and MRI modality at the same time. The nanoprobes with FI-MRI dual-modality do not only overcome drawbacks of singlemodality probes, but also compensate multi-drawbacks. The dual-modality nanoprobes can accurately label and track CSCs, and can display the spatial distribution of BCSCs in solid BC tumors. These can afford strong clinical foundation for further studying diagnosis, treatment and recurrence of $\mathrm{BC}$ at early stage.

\footnotetext{
Abbreviations

BC: breast cancer; CSCs: cancer stem cells; BCSCs: breast cancer stem cells; MRI: magnetic resonance imaging; Fl: fluorescence imaging; DTPA-Gd: gadopentetatedimeglumine; SPION: superparamagnetic iron oxide; PLGA: superparamagnetic poly(lactic-co-glycolic acid); NPs: nanoparticles; RBITC: rhodamine B isothicyanate; FA: folate; QD: quantum dot; PEG: polyethylene glycol; NS: nanoshells; ICG: indocyanine green; DOX: doxorubicin; Dy $\mathrm{SiO}_{2}$ : rhodamine-dye-doped silica; MEIO: magenetism engineered iron oxide; MFNPs: multifunctional nanoprobes; mMSCs: mouse mesenchymal stem cells; MNPs: magnetic nanoparticles; hMSCs: human mesenchymal stem cells.
}

\section{Authors' contributions}

HC, YW, TW carried out the literature collection, classification, writing and revising the manuscript; DS carried out the literature collection, classification, writing, and participated in the sequence alignment; Prof. ZS participated in the design of the study. Prof. CX and Dr. BW conceived of the study, and participated in its design and coordination and helped to draft, revise the manuscript. All authors read and approved the final manuscript.

\section{Authors' information}

Prof. Chunhui Xia is currently a professor in the College of Pharmacy at Qiqihar Medical University. He received her B.S. degree in Chemistry Education from Qiqihar Teachers College, M.S. degree in Inorganic Chemistry from Heilongjiang University, and Ph.D. degree in Materials Physics and Chemistry from Jilin University, China, in 1991, 2004 and 2011, respectively. His current research interest is primarily in antitumor effects of nanomaterials.

Dr. Baiqi Wang is an associate professor at the Department of Occupational and Environmental Health of Tianjin Medical University (TMU) of China. He received his PhD in Applied Chemistry from Harbin Institute of Technology in 2006. Then he worked as a postdoctoral fellow at State Key Laboratory For Artificial Microstructure and Mesoscopic Physics in Peking University. After 2 years, he joined TMU as faculty. In 2013, he worked in School of Medicine of the Johns Hopkins University as a visiting scholar. His research interests include synthesis, modification of new functionalized nanomaterials and their applications in cancer detection fields.

\section{Acknowledgements}

This work was financially supported by the Scientific Research Foundation from Education Department of Heilongjiang Province (No. 12541917).

\section{Competing interests}

We wish to confirm that there are no known conflicts of interest associated with this publication and there has been no significant financial support for this work that could have influenced its outcome.

We confirm that the manuscript has been read and approved by all named authors and that there are no other persons who satisfied the criteria for authorship but are not listed. We further confirm that the order of authors listed in the manuscript has been approved by all of us.

Received: 16 December 2015 Accepted: 20 May 2016

Published online: 23 June 2016

\section{References}

1. Siegel RL, Miller K, Jemal AJ. Cancer statistics, 2016. CA-Cancer J Clin. 2016;65:7-30.

2. Dennis JS, Gary MC, Steven GW, Wendy JL, Axel U, McGuire WL. Human breast cancer: correlation of relapse and survival with amplification of the HER-2/neu oncogene. Science. 1987;235:177-82.

3. Lin NU, Claus E, Sohl J, Razzak AR, Arnaout A, Winer EP. Sites of distant recurrence and clinical outcomes in patients with metastatic triple-negative breast cancer. Cancer. 2008;113:2638-45.

4. Early Breast Cancer. Trialist's Collaborative Group: effects of chemotherapy and hormonal therapy for early breast cancer on recurrence and 15-year survival: an overview of the randomised trials. Lancet. 2005;365:1687-717.

5. Reya T, Morrison SJ, Clarke MF, Weissman IL. Stem cells, cancer, and cancer stem cells. Nature. 2001;414:105-11.

6. Jordan CT, Guzman ML, Noble M. Cancer Stem Cells. N Engl J Med. 2006:355:1253-61.

7. Bonnet D, Dick JE. Human acute myeloid leukemia is organized as a hierarchy that originates from a primitive hematopoietic cell. Nat Med. 1997;3:730-7

8. Al-Hajj M, Wicha MS, Benito-Hernandez A, Morrison SJ, Clarke MF. Prospective identification of tumorigenic breast cancer cells. Proc Natl Acad Sci USA. 2003;100:3983-8.

9. Dean M, Fojo T, Bates S. Tumour stem cells and drug resistance. Nat Rev Cancer. 2005;5:275-84.

10. Hanahan D, Weinberg RA. The hallmarks of cancer. Cell. 2000;100:57-70. 
11. Tiffany MP, William HM, Frank P. The response of CD24(-/low)/ CD44 + breast cancer-initiating cells to radiation. J Natl Cancer I. 2006;98(24):1777-85.

12. Dick JE. Breast cancer stem cells revealed. Proc Natl Acad Sci USA. 2003;100:3547-9.

13. Christophe G, Min HH, Emmanuelle CJ, Florence M, Julie D, Marty B, Jocelyne J, Patrice V, Celina K, Suling L, Anne S, Dan H, Daniel B, Max SW, Gabriela D. ALDH1 is a marker of normal and malignant human mammary stem cells and a predictor of poor clinical outcome. Cell Stem Cell. 2007;1:555-67.

14. Hirschmann-Jax C, Foster AE, Wulf GG, Nuchtern JG, Jax TW, Goodell MA, Brenner MK. A distinct "side population" of cells with high drug efflux capacity in human tumor cells. Proc Natl Acad Sci USA. 2004; 101:14228-33.

15. Hu C, Xu L, Liang SJ, Zhang ZY, Zhang YY, Zhang FC. Lentivirus-mediated shRNA targeting Nanog inhibits cell proliferation and attenuates cancer stem cell activities in breast cancer. J Drug Target. 2016;24:422-32.

16. Karnoub AE, Dash AB, Vo AP, Sullivan A, Brooks MW, Bell GW, Richardson $A L$, Tubo R, Weinberg RA. Mesenchymal stem cells within tumour stroma promote breast cancer metastasis. Nature. 2007;449:557-63.

17. Sharma B, Varney ML, Saxena S, Wu LY, Singh RK. Induction of CXCR2 ligands, stem cell-like phenotype, and metastasis in chemotherapyresistant breast cancer cells. Cancer Lett. 2016;372:192-200.

18. Medintz IL, Uyeda HT, Goldman ER, Mattoussi H. Quantum dot bioconjugates for imaging, labelling and sensing. Nat Mater. 2005;4:435-46.

19. Bruchez M, Moronne M, Gin P, Weiss S, Alivisatos AP. Semiconductor nanocrystal as fluorescent biological labels. Science. 1998;281(25):2013-6.

20. Chan WC, Nie SM. Quantum dot bioconjugates for ultrasensitive nonisotopic detection. Science. 1998;281:2016-8.

21. Wu XY, Liu HJ, Liu JQ, Haley KN, Treadway JA, Larson JP, Ge N, Peale F, Bruchez MP. Immunofluorescent labeling of cancer marker Her2 and other cellular targets with semiconductor quantum dots. Nat Biotechnol. 2003:21:41-6.

22. Yezhelyev MV, Al-Hajj A, Morris C, Marcus Al, Liu T, Lewis M, Cohen C, Zrazhevskiy P, Simons JW, Rogatko A, Nie S, Gao X, O’Regan RM. In Situ Molecular Profiling of Breast Cancer Biomarkers with Multicolor Quantum Dots. Adv Mater. 2007;19:3146-51.

23. Chen C, Peng J, Xia HS, Yang GF, Wu QS, Chen LD, Zeng LB, Zhang ZL, Pang DW, Li Y. Quantum dots-based immunofluorescence technology for the quantitative determination of HER2 expression in breast cancer. Biomaterials. 2009;30:2912-8.

24. Liu XL, Peng CW, Chen C, Yang XQ, Hu MB, Xia HS, Liu SP, Pang DW, Li Y. Quantum dots-based double-color imaging of HER2 positive breast cancer invasion. Biochem Biophys Res Commun. 2011;409:577-82.

25. Wang BQ, Chen HT, Yang R, Wang F, Zhou P, Zhang N. Highly fluorescent QD probes labeling hepatocellular carcinoma cells. RSC Adv. 2015:5:1841-5.

26. Kim S, Lim YT, Soltesz EG, De Grand AM, Lee J, Nakayama A, Parke JA, Mihaljevic T, Laurence RG, Dor DM, Cohn LH, Bawendi MG, Frangioni JV. Near-infrared fluorescent type II quantum dots for sentinel lymph node mapping. Nat Biotechnol. 2004;22:93-7.

27. Lee JH, Huh YM, Jun YW, Seo JW, Jang JT, Song HT, Kim S, Cho EJ, Yoon HG, Suh JS, Cheon J. Artificially engineered magnetic nanoparticles for ultra-sensitive molecular imaging. Nat Med. 2007;13:95-9.

28. Xiang QM, Wang LW, Yuan JP, Chen JM, Yang F, Li Y. Quantum dot-based multispectral fluorescent imaging to quantitatively study co-expressions of Ki67 and HER2 in breast cancer. Exp Mol Pathol. 2015;99:133-8.

29. Liu LF, Wu SM, Jing FX, Zhou HB, Jia CP, Li G, Cong H, Jin QH, Zhao JL. Bead-based microarray immunoassay for lung cancer biomarkers using quantum dots as labels. Biosens Bioelectron. 2016;80:300-6.

30. Pedram P, Mahani M, Torkzadeh-Mahani M, Hasani Z, Ju H. Cadimium sulfide quantum dots modified with the human transferrin protein siderophiline for targeted imaging of breast cancer cells. Microchim Acta. 2016;183:67-71.

31. Wang LW, Peng CW, Chen C, LiY. Quantum dots-based tissue and in vivo imaging in breast cancer researches: current status and future perspectives. Breast Cancer Res Treat. 2015;151:7-17.

32. Gao X, Cui Y, Levenson RM, Chung LW, Nie S. In vivo cancer targeting and imaging with semiconductor quantum dots. Nat Biotechnol. 2004;22:969-76.
33. Chang BX, Yang XJ, Wang F, Wang YS, Yang R, Zhang N, Wang BQ. Water soluble fluorescence quantum dot probe labeling liver cancer cells. J Mater Sci Mater Med. 2013;24:2505-8.

34. Smith AM, Dave S, Nie S, True L, Gao X. Multicolor quantum dots for molecular diagnostics of cancer. Expert Rev Mol Diagn. 2006;6:231-44.

35. Lauterbur PC, Lauterbur PC. Image formation by induced local interactions: examples employing nuclear magnetic resonance. Nature. 1973;242:190-1.

36. Fox MD, Raichle ME. Spontaneous fluctuations in brain activity observed with functional magnetic resonance imaging. Nat Rev Neurosci. 2007:8:700-11.

37. Jody LM, Thomas JM. Bioresponsive, cell-penetrating, and multimeric MR contrast agents. Acc Chem Res. 2009;42:893-903.

38. Kaiser W, Zeitler E. MR imaging of the breast: fast imaging sequences with and without Gd-DTPA. Preliminary observations. Radiology. 1989:170:681-6.

39. Wang BQ, Xia CH, Javed I, Tang NJ, Sun ZR, LVY, Wu L. Influences of Co doping on the structural, optical and magnetic properties of $\mathrm{ZnO}$ nanorods synthesized by hydrothermal route. Solid State Sci. 2009:11:1419-22.

40. Peng ML, Li HL, Luo ZY, Kong J, Wan YS, Zheng LM, Zhang QL, Niu HX, Vermorken A, Van de Wim V, Chen C, Zhang XK, Li FQ, Guo LL, Cui YL. Dextran-coated supermagnetic nanoparitcles as potential cancer drug carriers in vivo. Nanoscale. 2015;7:11155-62.

41. da Silva Nunes E, Carneiro ML, de Oliveira RG, Báo SN, de Souza AR. Colloidal stability, surface characterisation and intracellular accumulation of Rhodium (II) citrate coated superparamagnetic iron oxide nanoparticles in breast tumour: a promising platform for cancer therapy. J Nanopart Res. 2013;15(6):1-5.

42. Lai SM, Hsiao JK, Yu HP, Lu CW, Huang CC, Shieh MJ, Lai PS. Polyethylene glycol-based biocompatible and highly stable superparamagnetic iron oxide nanoclusters for magnetic resonance imaging. J Mater Chem 2012:22:15160-7.

43. Lu Y, Yin YD, Mayers BT, Xia YN. Modifying the surface properties of superparamagnetic iron oxide nanoparticles through a Sol - Gel approach. NanoLett. 2002;2:183-6.

44. Jafari A, Salouti M, Shayesteh SF, Heidari Z, Rajabi AB, Boustani K, Nahardani A. Synthesis and characterization of biombesin-superparamagnetic iron oxide nanoparticles as a targeted contrast agent for imaging of breast cancer using MRI. Nanotechnology. 2015;26:075101.

45. Sun Y, Zheng Y, Ran H, Zhou Y, Shen H, Chen Y, Chen H, Krupka TM, Li A, Li P, Wang Z, Wang Z. Corrigendum to "Superparamagnetic PLGA-iron oxide microcapsules for dual-modality US/MR imaging and high intensity focused US breast cancer ablation". Biomaterials. 2012;33:5854-64.

46. Shiozawa M, Kobayashi S, Sato Y, Maeshima H, Hozumi Y, Lefor AT, Kurihara K, Sata N, Yasuda Y. Magnetic resonance lymphography of sentinel lymph in patients with breast cancer using supermagnetic iron oxide: a feasibility study. Breast Cancer. 2014;21:394-401.

47. Nakai G, Matsuki M, Harada T, Tanigawa N, Yamada T, Barentsz J, Narumi Y. Evaluation of axillary lymph nodes by diffusion-weighted MRI using ultrasmall superparamagnetic iron oxide in patients with breast cancer: initial clinical experience. J Magn Reson Imaging. 2011;34:557-62.

48. Shan XH, Wang P, Xiong F, Gu N, Hu H, Qian W, Lu HY, Fan Y. MRI of high-glucose metabolism tumors: a study in cells and mice with 2-DGModified superparamagnetic iron oxide nanoparticles. Mol Imaging Bio. 2016;18:24-33

49. Crich SG, Biancone L, Cantaluppi V, Duo D, Esposito G, Russo S, Camussi G, Aime S. Improved route for the visualization of stem cells labeled with a Gd-/Eu-chelate as dual (MRI and fluorescence) agent. Magnet Reson Med. 2004:51:938-44.

50. Wilhelm C, Cebers A, Bacri JC, Gazeau F. Deformation of intracellular endosomes under a magnetic field. Eur Biophys J Biophy. 2003;32:655-60.

51. Yang $H$, Zhuang YM, Hu H, Du XX, Zhang CX, Shi XY, Wu HX, Yang SP. Silica-coated manganese oxide nanoparticles as a platform for targeted magnetic resonance and fluorescence imaging of cancer cells. Adv Funct Mater. 2010;20:1733-41.

52. Gao GH, Heo H, Lee JH, Lee DS. An acidic pH-triggered polymeric micelle for dual-modality MR and optical imaging. J Mater Chem. 2010;20:5454-61. 
53. Li JJ, You J, Dai Y, Shi ML, Han CP, Xu K. Gadolinium Oxide Nanoparticles and Aptamer-Functionalized Silver Nanoclusters-Based Multimodal Molecular Imaging Nanoprobe for Optical/Magnetic Resonance Cancer Cell Imaging. Anal Chem. 2014;86:11306-11.

54. Kosaka N, Bernardo M, Mitsunaga M, Choyke PL, Kobayashi H. MR and optical imaging of early micrometastases in lymph nodes: triple labeling with nano-sized agents yielding distinct signals. Contrast Media Mol Imaging. 2012;7:247-53.

55. Kievit FM, Stephen ZR, Veiseh O, Arami H, Wang T, Lai VP, Park JO, Ellenbogen RG, Disis ML, Zhang M. Targeting of primary breast cancers and metastases in a transgenic mouse model using rationally designed multifunctional SPIONs. ACS Nano. 2012;6:2591-601.

56. Bardhan R, Chen WX, Perez-Torres C, Bartels M, Huschka RM, Zhao LL, Morosan E, Pautler RG, Joshi A, Halas NJ. Nanoshells with targeted simultaneous enhancement of magnetic and optical imaging and photothermal therapeutic response. Adv Funct Mater. 2009;19:3901-9.

57. Ji EL, Nohyun L, Hyoungsu K, Jaeyun K, Seung HC, Jeong HK, Taeho K, In CS, Seung PP, Woo KM, Taeghwan H. Uniform mesoporous dye-doped silica nanoparticles decorated with multiple magnetite nanocrystals for simultaneous enhanced magnetic resonance imaging, fluorescence imaging, and drug delivery. J Am Chem Soc. 2010;132:552-7.

58. Lee JH, Jun YW, Yeon SI, Shin JS, Cheon J. Dual-mode nanoparticle probes for high-performance magnetic resonance and fluorescence imaging of neuroblastoma. Angew Chem Int Ed. 2006;45:8160-2.

59. Robert MT, Dale LH, Todd CM, Abdul-Mehdi SA, Macro B, Laurel OS. Multifunctional iron platinum stealth immunomicelles: targeted detection of human prostate cancer cells using both fluorescence and magnetic resonance imaging. J Nanopart Res. 2011;13:4717-29.

60. Hong H, Wang F, Zhang Y, Graves SA, Eddine SBZ, Yang YA, Theuer CP, Nickles RJ, Wang XD, Cai WB. Red fluorescent zinc oxide nanoparticle: a novel platform for cancer targeting. ACS Appl Mater Inte. 2015;7:3373-81.

61. Huang P, Li ZM, Lin J, Yang DP, Gao G, Xu C, Bao L, Zhang CL, Wang K, Song $\mathrm{H}, \mathrm{Hu} \mathrm{H}$, Cui DX. Photosensitizer-conjugated magnetic nanoparticles for in vivo simultaneous magnetofluorescent imaging and targeting therapy. Biomaterials. 2011;32:3447-58.

62. Kumar R, Nyk M, Ohulchanskyy TY, Flask CA, Prasad PN. Combined optical and MR bioimaging using rare earth ion doped nayf4 nanocrystals. Adv Funct Mater. 2009;19:853-9.

63. Chung KH, Cho MY, Sung MH, Poo H, Lim YT. Electrostatically assembled biocompatible polymer nanoparticles for MR/optical dual-modality imaging nanoprobes. Chem Commun. 2011;47:8889-91.

64. Cho HJ, Yoon HY, Koo H, Ko SH, Shim JS, Cho JH, Park JH, Kim K, Kwon IC, Kim DD. Hyaluronic acid-ceramide-based optical/MR dual imaging nanoprobe for cancer diagnosis. J Control Release. 2012;162:111-8.

65. Wu SC, Lin KL, Wang TP, Tzou SC, Singh G, Chen MH, Cheng TL, Chen CY, Liu GC, Lee TW, Hu SH, Wang YM. Imaging specificity of MR-optical imaging agents following the masking of surface charge by poly(ethylene glycol). Biomaterials. 2013;34:4118-27.
66. Tassa C, Shaw SY, Weissleder R. Dextran-coated iron oxide nanoparticles: a versatile platform for targeted molecular imaging, molecular diagnostics, and therapy. Accounts Chem Res. 2011;44:842-52.

67. Wen $X$, Wang $Y$, Zhang F, Zhang $X$, Lu L, Shuai $X$, Shen J. In vivo monitoring of neural stem cells after transplantation in acute cerebral infarction with dual-modal MR imaging and optical imaging. Biomaterials. 2014;35:4627-35

68. Cheng L, Wang C, Ma XX, Wang QL, Cheng Y, Wang H, Li YG, Liu Z. Multifunctional upconversion nanoparticles for dual-modal imaging-guided stem cell therapy under remote magnetic control. Adv Funct Mater. 2013;23:272-80.

69. Sung CK, Hong KA, Lin S, Lee Y, Cha J, Lee JK, Hong CP, Han BS, Jung SI, Kim SH, Kang Yoon S. Dual-modal nanoprobes for imaging of mesenchymal stem cell transplant by MRI and fluorescence imaging. Korean J Radiol. 2009;10:613-22.

70. Park W, Yang HN, Ling D, Yim H, Kim KS, Hyeon T, Na K, Park KH. Multi-modal transfection agent based on monodisperse magnetic nanoparticles for stem cell gene delivery and tracking. Biomaterials. 2014;35:7239-47.

71. Simonetta GC, Luigi B, Vincenzo C, Debora D, Esposito G, Simona R, Giovanni $C$, Silvio A. Improved route for the visualization of stem cells labeled with a Gd-/Eu-chelate as dual (MRI and fluorescence) agent. Magnetic Reson Med. 2004;51:938-44.

72. Elizabeth JS, Tobias DH, Sophie B, Stavros D, Christian K, Reinhardt M, John K, Shoujun Z, Rick B, Sheida S, Heike DL. In vivo magnetic resonance imaging and optical imaging comparison of viable and nonviable mesenchymal stem cells with a bifunctional label. Mol Imaging 2010;9:278-90.

73. Shen J, Zhong XM, Duan XH, Cheng LN, Hong GB, Bi XB, Liu Y. Magnetic resonance imaging of mesenchymal stem cells labeled with dual (MR and fluorescence) agents in rat spinal cord injury. Acad Radiol. 2009;16(9):1142-54.

74. Vuu K, Xie J, McDonald MA, Bernardo M, Hunter F, Zhang Y, Li K, Bednarski M, Guccione S. Gadolinium-rhodamine nanoparticles for cell labeling and tracking via magnetic resonance and optical imaging. Bioconjug Chem. 2005;16:995-9.

75. Sutton EJ, Henning TD, Boddington S, Demos S, Krug C, Meier R, Kornak J, Zhao S, Baehner R, Sharifi S, Daldrup-Link H. In vivo magnetic resonance imaging and optical imaging comparison of viable and nonviable mesenchymal stem cells with a bifunctional label. Mol Imaging. 2010;9:278-90.

76. Lee K, Park C, Moon HY, Ahn E, Park HE, Ihm SH, Seung KB, Yoon TJ, Chang K, Lee C, Cheong C, Kwan SH. Magnetic resonance tracking of multifunctional nanoparticle-labeled mouse mesenchymal stem cells in a mouse model of myocardial infarction. Curr Appl Phys. 2009;9:S12-4.

\section{Submit your next manuscript to BioMed Central and we will help you at every step:}

- We accept pre-submission inquiries

- Our selector tool helps you to find the most relevant journal

- We provide round the clock customer support

- Convenient online submission

- Thorough peer review

- Inclusion in PubMed and all major indexing services

- Maximum visibility for your research

Submit your manuscript at www.biomedcentral.com/submit 